Cite this: Analyst, 2013, 138, 6488

Received 7th June 2013

Accepted 5th September 2013

DOI: 10.1039/c3an01141k

www.rsc.org/analyst

\title{
Extruded polymer films pigmented with a heterogeneous ion-pair based lumophore for $\mathrm{O}_{2}$ sensing
}

\begin{abstract}
Andrew Mills* and Ashleigh Graham
A novel approach to polymeric $\mathrm{Ru}(I)$-diimine luminescent $\mathrm{O}_{2}$ sensors is described. The $\mathrm{Ru}(I)$-diimine, tris(4,7-diphenyl-1,10-phenanthroline)ruthenium(॥) dichloride $\left(\left[R u(d p p)_{3}\right]^{2+}\right)$, is first ion-paired to the surface of heterogeneous $\mathrm{TiO}_{2}$ particles, rendered negatively charged due to the alkali nature of the aqueous solution, to produce an $\mathrm{O}_{2}$ sensitive pigment with a strikingly high oxygen sensitivity (i.e. $\mathrm{PO}_{2}$ $(S=1 / 2)=0.002 \mathrm{~atm}$, where $\mathrm{PO}_{2}(S=1 / 2)$ is defined as the amount of oxygen required to reduce the initial, oxygen free luminescence by $50 \%$ ), and a rapid response to oxygen. The pigment is extruded in low density polyethylene (LDPE) to produce a thin $(60 \mu \mathrm{m})$, flexible, $\mathrm{O}_{2}$ sensing plastic film, with an $\mathrm{O}_{2}$ sensitivity $\left(\mathrm{PO}_{2}(S=1 / 2)=0.84 \mathrm{~atm}\right)$ comparable to the more traditional homogeneous lumophore ionpair based $\mathrm{O}_{2}$ sensor ink films reported in the literature.
\end{abstract}

$$
I_{0} / I=\tau_{0} / \tau-\left(1=K_{\mathrm{SV}}\left[\mathrm{O}_{2}\right]\right)
$$

\section{Introduction}

The detection and quantification of oxygen is of great importance in many industries and practical applications, not least environmental monitoring, medical applications, and more recently, food packaging. ${ }^{1-3}$ Research into $\mathrm{O}_{2}$ detection has increasingly moved away from the more traditional Clark electrode $^{4}$ and GC analysis, which is limited by its expense and bulkiness, towards optical detection. Most optical sensors for oxygen are based on luminescence quenching, and within the area of such luminescence-based $\mathrm{O}_{2}$ sensors, two main dye groups have been studied as the $\mathrm{O}_{2}$ quenchable lumophores, namely: platinum and palladium metal porphyrins, and ruthenium $\alpha$-diimines. The latter are favoured because of their large Stokes shift, high quantum yield of luminescence, and high photostability, ${ }^{5}$ although the former have generally higher sensitivities (especially the Pd porphyrins). ${ }^{6}$ These complexes are quenched by molecular oxygen and so, upon exposure to $\mathrm{O}_{2}$ the lifetime and luminescence intensity of the lumophore decreases, i.e.

$$
\begin{gathered}
\mathrm{D}+h v \rightarrow \mathrm{D}^{*} \\
\mathrm{D}^{*}+\mathrm{O}_{2} \rightarrow \mathrm{D}+\mathrm{O}_{2}^{*}
\end{gathered}
$$

In homogeneous media, such as aqueous solution, this quenching is found to obey the linear Stern-Volmer equation, eqn (2), where $I_{0}$ (and $\tau_{0}$ ) and $I$ (and $\tau$ ) are the luminescence intensities (and lifetimes) in the absence and presence of oxygen, respectively, and $K_{\mathrm{SV}}$ is the Stern-Volmer constant.

School of Chemistry and Chemical Engineering, Queen's University, Stranmillis Road, Belfast, BT9 5AG, UK. E-mail: andrew.mills@qub.ac.uk; Fax: +44 (0)28 90976524 ; Tel: +44 (0)28 90974339
Usually, when these $\mathrm{Ru}(\mathrm{II})$-diimine complexes are used in $\mathrm{O}_{2}$ sensors, they are immobilized as a homogeneous ion-pair with a lipophilic anion, such as tetraphenyl borate, in a hydrophobic encapsulating medium, such as a polymer. ${ }^{7}$ More often than not, upon encapsulation, the quenching behaviour of these complexes no longer obeys the linear Stern-Volmer relationship, but instead exhibits a negative deviation from linearity and a new kinetic model is required to fit the quenching data. Probably the most commonly accepted and widely used model to fit such data is the two-site model, ${ }^{\mathbf{8} 9}$ reported by Demas and co-workers, in which it is assumed that the lumophore exists in two different microdomains within the encapsulating medium, with each microdomain associated with a different quenching response by the lumophore contained therein. The modified Stern-Volmer equation for this system is given in eqn (3), where $f_{01}$ and $f_{02}$ are the fractions of the dye molecules in the two different microdomains, the sum of which is unity, and $K_{\mathrm{SV} 1}$ and $K_{\mathrm{SV} 2}$ are the Stern-Volmer constants of the lumophore in these two microdomains. Although the model is based on two different $\mathrm{O}_{2}$-quenching microdomains, it is recognised as a likely gross oversimplification of the true nature of the system. ${ }^{8}$ However, eqn (3) does provide a good fit to most data sets generated by lumophores in polymer based $\mathrm{O}_{2}$ sensors.

$$
I / I_{0}=f_{01} /\left(1+K_{\mathrm{SV} 1}\left[\mathrm{O}_{2}\right]\right)+f_{02} /\left(1+K_{\mathrm{SV} 2}\left[\mathrm{O}_{2}\right]\right)
$$

One of the earliest $\mathrm{O}_{2}$ sensors based on $\left[\mathrm{Ru}(\mathrm{dpp})_{3}\right]^{2+}$, was reported by Wolfbeis et al., in $1986,{ }^{10}$ and incorporates the lumophore into silica gel beads ( 5 microns diameter with $30 \mathrm{~nm}$ pores), which were then dried, homogenously mixed with a silicone prepolymer, cured for $12 \mathrm{~h}$ at $40{ }^{\circ} \mathrm{C}$, and the volume 
Table 1 Examples of oxygen sensors based on $\left[\mathrm{Ru}(\mathrm{dpp})_{3}\right]^{2+}$

\begin{tabular}{|c|c|c|c|c|c|c|}
\hline Ion-pair & Encapsulating polymer & $f_{01}$ & $K_{\mathrm{SV} 1}\left(\mathrm{~atm}^{-1}\right)$ & $K_{\mathrm{SV} 2}\left(\mathrm{~atm}^{-1}\right)$ & $\mathrm{PO}_{2}(S=1 / 2)(\mathrm{atm})$ & Ref. \\
\hline$\left[\mathrm{Ru}(\mathrm{dpp})_{3} \mathrm{Cl}_{2}\right]$ in silica beads & Silicone, E43 & 0.83 & 9.13 & 0.17 & 0.16 & 10 \\
\hline$\left.\left[\mathrm{Ru}(\mathrm{dpp})_{3} \mathrm{ClO}_{4}\right)_{2}\right]$ & Silicone, RTV-118 & 0.88 & 53.65 & 4.67 & 0.02 & 12 \\
\hline$\left[\mathrm{Ru}(\mathrm{dpp})_{3}(\mathrm{TSPS})_{2}\right]$ & Silicone, E4 & 0.28 & 15.69 & 0.60 & 0.83 & 11 \\
\hline$\left[\mathrm{Ru}(\mathrm{dpp})_{3}\left(\mathrm{Ph}_{4} \mathrm{~B}\right)_{2}\right]$ & Cellulose acetate & 0.7 & 20.44 & 1.76 & 0.09 & 13 \\
\hline$\left[\mathrm{Ru}(\mathrm{dpp})_{3}\left(\mathrm{ClO}_{4}\right)_{2}\right]$ & Silicone, RTV-118 & 0.98 & 29.25 & 1.22 & 0.04 & 14 \\
\hline$\left[\mathrm{Ru}(\mathrm{dpp})_{3}\left(\mathrm{Ph}_{4} \mathrm{~B}\right)_{2}\right]$ & PMMA & 0.98 & 23.53 & 0.001 & 0.04 & 7 \\
\hline
\end{tabular}

inside the silica beads - now in a cured silicone membrane then filled with water by dipping the sensor membrane in boiled water. It is possible in this work that the silica initially binds the $\left[\mathrm{Ru}(\mathrm{dpp})_{3}\right]^{2+}$ electrostatically, although the authors note the silica has 'a low ion-exchanging capacity' and the need for a film hydration step and to store the film in an aqueous or moist environment, suggests that the dye might be instead simply adsorbed as the dichloride salt onto the internal surfaces of the silica beads. Whatever the binding, these films suffer problems of low luminescence and a tendency for the lumophore to undergo self-quenching of luminescence when its concentration exceeds a critical value. ${ }^{11}$

Given these difficulties, other means of encapsulating $\left[\mathrm{Ru}(\mathrm{dpp})_{3}\right]^{2+}$ into a lipophilic polymer, such as silicone, were investigated subsequently, and now most $\mathrm{O}_{2}$ sensors utilise this lumophore in a form in which it is electrostatically bound as an ion-pair to a lipophilic anion, such as perchlorate, dodecyl sulphate $\left(\mathrm{DS}^{-}\right)$, tetramethylsilypropansulfonate $\left(\mathrm{TSPS}^{-}\right)$or tetraphenyl borate $\left(\mathrm{Ph}_{4} \mathrm{~B}^{-}\right)$. These are homogeneous ion-pair lumophores, many examples of which are given in Table 1 (ref. 7 and 10-16) and, not surprisingly, these ion-pair, lipophilic lumophores are a major feature of most commercial $\mathrm{O}_{2}$ optical sensors (e.g. OxySense ${ }^{17}$ ) and pressure sensitive paints. ${ }^{18}$

Two of the examples in Table 1 utilise the one component, acetic acid releasing, prepolymer, E4 from Wacker (Burhausen, Germany) to encapsulate the $\left[\mathrm{Ru}(\mathrm{dpp})_{3}\right]^{2+}$ homogeneous ionpair. This prepolymer, as with many silicone prepolymers, contains a hydrophobic silica gel as a filler. ${ }^{11}$ The latter is prepared from hydrophilic silica via a reaction of the surface silanol groups with an organosilane, to generate Si-R surface groups, so rendering the material hydrophobic. Klimant and Wolfbeis note that with their numerous homogeneous $\left[\mathrm{Ru}(\mathrm{dpp})_{3}\right]^{2+}$ ion-pair sensors based on $\mathrm{E} 4$, 'the lumophore doesn't accumulate at the filler/silicone interface', presumably based on the observation that the 'quenching constants are similar for sensor membranes based on silicones containing either silica gel as filler or no filler'. ${ }^{9}$ Thus, in $\mathrm{O}_{2}$ sensors containing hydrophobic silica as a filler, there is no evidence that the lumophore is in anything but its homogeneous ion-pair form.

Most oxygen sensors based on the ruthenium diimine lumophores, with and without filler, exhibit a negative deviation from linearity in the Stern-Volmer plots of the observed luminescence data as a function of $\mathrm{O}_{2}$ concentration. As a consequence the data is often fitted to eqn (3), values for which (i.e. $f_{01}, K_{\mathrm{SV} 1}$ and $K_{\mathrm{SV} 2}$ ) are given in Table 1 for the various $\left[\mathrm{Ru}(\mathrm{dpp})_{3}\right]^{2+}$-based $\mathrm{O}_{2}$ sensors. Although formally sensitivity is defined as signal change/concentration, in systems in which a non-linear response curve is generated this formal definition is not considered particularly useful. ${ }^{19}$ Thus, with regard to $\mathrm{O}_{2}$ sensors, others ${ }^{20}$ have used the ratio, $R=I_{0} / I_{100}$, as a measure of sensitivity, where $I_{100}$ is the luminescence signal in $100 \% \mathrm{O}_{2}$. Here, as elsewhere, ${ }^{7}$ we use the parameter, $\mathrm{PO}_{2}(S=1 / 2)$ as a rough measure of sensitivity of $\mathrm{O}_{2}$ sensors, which is defined as: the level of oxygen required for a $50 \%$ reduction in luminescence intensity. A brief examination of Table 1 reveals the $\left[\mathrm{Ru}(\mathrm{dpp})_{3}\right]^{2+} /$ silicone rubber $\mathrm{O}_{2}$-sensor of Bacon and Demas, ${ }^{12}$ with a $\mathrm{PO}_{2}(S=1 / 2)=0.02 \mathrm{~atm}$, to be one of the most sensitive of all the $\mathrm{O}_{2}$ sensitive inks based on $\left[\mathrm{Ru}(\mathrm{dpp})_{3}\right]^{2+}$ that have been reported to date.

In contrast to most of the examples in Table 1, in this paper we present a novel method of luminescent, $\mathrm{Ru}(\mathrm{II})$-diiminebased $\mathrm{O}_{2}$ sensor fabrication, in which the cationic, lumophoric dye, $\left[\mathrm{Ru}(\mathrm{dpp})_{3}\right]^{2+}$, is ion-paired to the surface of heterogeneous $\mathrm{TiO}_{2}$ nanoparticles in aqueous solution, which have been rendered anionic through the exploitation of the pzc (point of zero charge) of the $\mathrm{TiO}_{2}(\sim \mathrm{pH} 6)$. After filtering, the result is a pigment, which can then be extruded in LDPE to produce a thin $(60 \mu \mathrm{m})$, highly flexible, luminescence-based $\mathrm{O}_{2}$ sensitive plastic film. Such heterogeneous $\mathrm{O}_{2}$ sensors overcome the problems associated with the more traditional, homogeneous ion-pair lumophore $\mathrm{O}_{2}$-sensitive inks, such as film curling ${ }^{12}$ and the need for a solid, largely inflexible support (such as glass or Mylar). ${ }^{11,12,15,16}$

\section{Experimental}

\subsection{Materials and instrumentation}

The $\left[\mathrm{Ru}(\mathrm{dpp})_{3}\right]^{2+}$, in its dichloride salt form, was purchased from GFS Chemicals, and used as received. The P25 $\mathrm{TiO}_{2}$ powder was a gift from Evonik Industries, and comprised particles with a primary size of $21 \mathrm{~nm}$, in turn comprised of an intimate mixture of $75 \%$ anatase and $25 \%$ rutile crystalline phases. $^{21}$ Titania was chosen as the inorganic support, over silica (pzc $\sim 3$ ) due to its higher surface density of ionisable protons (12.5 cf. 5.9 sites per $\mathrm{nm}^{2}$ based on surface crystal structure calculations). ${ }^{22}$ The low density polyethylene, LDPE, powder (for masterbatch work) had a melt flow index (MFI) of 20 was supplied by PW Hall UK and the LDPE for film preparation 
had an MFI of 4 (lupolen $3020 \mathrm{~K}$ ) and was supplied as pellets by Ultrapolymers UK.

LDPE has been used as an $\mathrm{O}_{2}$ lumophore encapsulating material before. ${ }^{23}$ In this, and other examples, ${ }^{12}$ the $\mathrm{O}_{2}$-sensitive lumophore (ref. 23 used fluoranthene) is incorporated into the polymer film by soaking the film in a volatile organic solvent, such as cyclohexane, in which the lumophore is dissolved. The solvent causes the polymer film to swell and adsorb some of the solution and rapid drying then leaves some of the dye entrapped in the polymer. Since this approach requires the lumophore to be lipophilic, it follows that such indicators are examples of homogeneous $\mathrm{O}_{2}$ sensing lumophoric systems. One problem with such systems is the tendency for the lumophore to crystallise over time. ${ }^{11}$

All gases were purchased from BOC gases and blended using a Cole Parmer gas blender. All fluorescence work was carried out using a PerkinElmer LS45 Fluorescence Spectrometer. The pigmented polymer film was extruded using a Rondol Microlab Twin Screw extruder.

\subsection{Preparation of intelligent pigments}

The cationic nature of the $\left[\mathrm{Ru}(\mathrm{dpp})_{3}\right]^{2+}$ dye and the point of zero charge (pzc) of the $\mathrm{TiO}_{2}$ (pH 6.6) were exploited in order to ionpair the dye to the surface of the titania particles. Thus, at $\mathrm{pH}$ 11 , the $\mathrm{TiO}_{2}$ forms surface $\equiv \mathrm{Ti}-\mathrm{O}^{-}$groups, (the latter is a common representation ${ }^{24}$ of such surface groups, in this case with the Ti forming 3 bonds to three different atoms in the bulk and one to a surface oxygen) to which the cationic dye can bind via ion-pairing, i.e.

$$
2 \equiv \mathrm{Ti}-\mathrm{O}^{-}+\left[\mathrm{Ru}(\mathrm{dpp})_{3}\right]^{2+} \rightarrow\left[\left(\equiv \mathrm{Ti}-\mathrm{O}^{-}\right)_{2}\left(\mathrm{Ru}(\mathrm{dpp})_{3}\right]\right.
$$

Hence, typically, to $100 \mathrm{ml}$ of a $10^{-4} \mathrm{M}$ solution of the dye in $10^{-3} \mathrm{M} \mathrm{NaOH}$ (i.e. at $\mathrm{pH} 11$ ) were added $5 \mathrm{~g}$ of $\mathrm{P} 25 \mathrm{TiO}_{2}$, the mixture was stirred for 2 hours, filtered, air dried, and the resulting solid washed with three $10 \mathrm{ml}$ aliquots of a $10^{-3} \mathrm{M}$ $\mathrm{NaOH}$ aqueous solution. The pale yellow/orange powdered solid product was allowed to air dry for a few hours before being transferred to an oven $\left(50^{\circ} \mathrm{C}\right)$ for 1 hour, ground with a mortar and pestle, and sieved through a $250 \mu \mathrm{m}$ sieve. The final, fine, evenly coated, yellow powder luminesced brightly under UV light in the absence of $\mathrm{O}_{2}$.

\subsection{Preparation of $\mathrm{O}_{2}$-sensitive plastic films}

The $\mathrm{O}_{2}$-sensitive plastic films were fabricated by the extrusion of the $\mathrm{TiO}_{2}-\left[\mathrm{Ru}(\mathrm{dpp})_{3}\right]^{2+}$ pigment powder in low density polyethylene (LDPE), with a final pigment loading of $5 \mathrm{wt} \%$, using a Rondol Microlab $10 \mathrm{~mm}$ twin screw extruder (barrel L/D 25/1). The pigment was first dispersed through LDPE powder (melt flow index, MFI, 20) to produce a masterbatch of pigmented pellets with $10 \mathrm{wt} \%$ pigmentation, using the extruder to create masterbatch pellets at processing temperatures ramped gradually from $90{ }^{\circ} \mathrm{C}$ at the feed zone, to $140{ }^{\circ} \mathrm{C}$ at the die, using a feed hopper rate of $41 \mathrm{rpm}$, extruder screw speed of $80 \mathrm{rpm}$ and a pelletizer speed of $0.5 \mathrm{~m} \mathrm{~min}^{-1}$. These pellets were then diluted by $50 \%$ w/w with virgin LDPE pellets (MFI 4) and

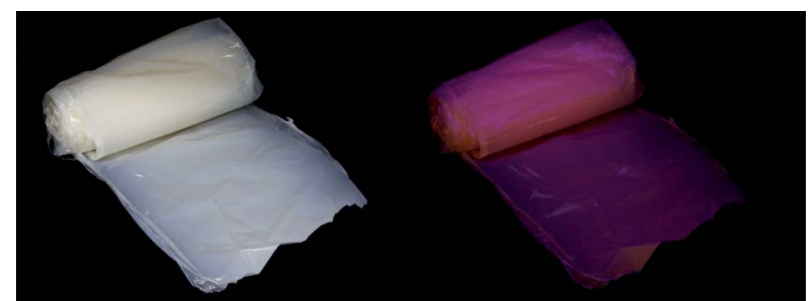

Fig. 1 Photographs of the $\mathrm{TiO}_{2}-\left[\mathrm{Ru}(\mathrm{dpp})_{3}\right]^{2+}$ pigmented extruded LDPE film in air under room light, and under UV light.

extruded to produce a cast film at the following processing conditions: temperatures starting at $90{ }^{\circ} \mathrm{C}$ (at the feed zone) then increasing to: $110-125-135{ }^{\circ} \mathrm{C}$ (across the barrel) and finally $140{ }^{\circ} \mathrm{C}$ (at the die), at a feed hopper rate of $41 \mathrm{rpm}$, extruder screw speed of $100 \mathrm{rpm}$, and take-off speed of $1.5 \mathrm{~m}$ $\min ^{-1}$. The average, central thickness of the $\mathrm{O}_{2}$-sensitive LDPE film was measured by micrometry to be $60 \mu \mathrm{m}$. The $\mathrm{TiO}_{2}-$ $\left[\mathrm{Ru}(\mathrm{dpp})_{3}\right]^{2+}$ pigmented extruded LDPE film was a pale yellow colour and luminesced brightly under UV light even in air, as illustrated in Fig. 1.

\subsection{Characterization}

For luminescence intensity measurements, the pigment and plastic film were both mounted on a microscope slide using double-sided tape, which in turn was cut to fit the diagonal of a typical $1 \mathrm{~cm}$ quartz fluorescence cell. In order to maximise the measured luminescence intensity of these solid-state polymer film samples, the slide was placed in the cuvette, and positioned so that the edge of the sensor films was directly in line with the emission detector of the fluorimeter and so square on to the excitation beam, allowing the luminescence, which was mostly gathered by total internal reflection, and exits from the edge of the film, to be more easily measured.

2.4.1 Oxygen sensitivity. The emission spectrum of a typical sample (pigment or film) on a microscope slide was recorded after 1 minute purging of a rubber septum sealed fluorescence cell with gas blends containing different, known, levels of argon and oxygen; with $\lambda_{\text {excitation }}$ always set at $430 \mathrm{~nm}$. The desired $\mathrm{O}_{2} / \mathrm{Ar}$ mixtures/blends were generated using a Cole-Parmer gas blender fitted with $150 \mathrm{~mm}$ flow tubes, and fed by separate streams of pure $\mathrm{Ar}$ and $\mathrm{O}_{2}$. The cycles of response-recovery curves were generated by using the fluorimeter in the timedrive mode, which allows the luminescence intensity at one wavelength (typically $615 \mathrm{~nm}$ for the pigment, and $600 \mathrm{~nm}$ for the extruded film) to be recorded as a function of time.

2.4.2 Lifetime measurements. The lifetime measurements were carried out using an in-house built nanosecond flash photolysis system. Briefly, the system comprised a Continuim Surelite I-10 Nd-YAG laser connected to a Surelite Separator Package (SSP), as the excitation source used to excite the sample film in the sample chamber. The luminescence produced by laser excitation of the sample was detected using a system comprising a monochromator coupled to a photomultiplier tube (PMT) detector. The laser was used at a power of $\sim 5 \mathrm{~mW}$, 
with a $355 \mathrm{~nm}$ dichroic mirror in place, and the monochromator set at $600 \mathrm{~nm}$ (the maximum wavelength of emission for most of the indicator films). The pulse had an energy of $5 \mathrm{~mJ}$, and a pulse width of 4-6 ns, and the samples were positioned as per the fluorimetry work, i.e. approximately perpendicular to the excitation light.

\section{Results and discussion}

\section{1 $\mathrm{TiO}_{2}-\left[\mathrm{Ru}(\mathrm{dpp})_{3}\right]^{2+}$ pigment as an $\mathrm{O}_{2}$ indicator}

Upon excitation at $430 \mathrm{~nm}$, the emission maximum of the $\mathrm{TiO}_{2}-$ $\left[\mathrm{Ru}(\mathrm{dpp})_{3}\right]^{2+}$ pigment (adhered to a microscope slide using double-sided tape) was observed at $615 \mathrm{~nm}$. Quenching of this luminescence was monitored as a function of partial pressure of $\mathrm{O}_{2}, \mathrm{PO}_{2}$, and the resulting recorded emission spectra are shown in Fig. 2, with the corresponding Stern-Volmer plot shown as the inset diagram. As expected, a negative deviation from linearity was observed in this plot, so eqn (3) was used to model the data, and the resulting calculated optimum fit parameters are presented in Table 2.

These quenching parameters reveal the pigment to be extremely sensitive to oxygen, more so than the homogeneous, ion-pair, ink-based $\mathrm{O}_{2}$ sensors reported in Table 1; indeed, the calculated $\mathrm{PO}_{2}(S=1 / 2)(0.002$ atm) for the pigment (see Table 2) is ten times less than that of the Bacon and Demas ${ }^{12}$ silicone-based sensor (see Table 1). This is not too surprising given the $\mathrm{O}_{2}$-sensitive lumophoric dye is bound on the surface of the $\mathrm{TiO}_{2}$ pigment particles and so much more easily quenched by oxygen than when the homogeneous ion-paired dye

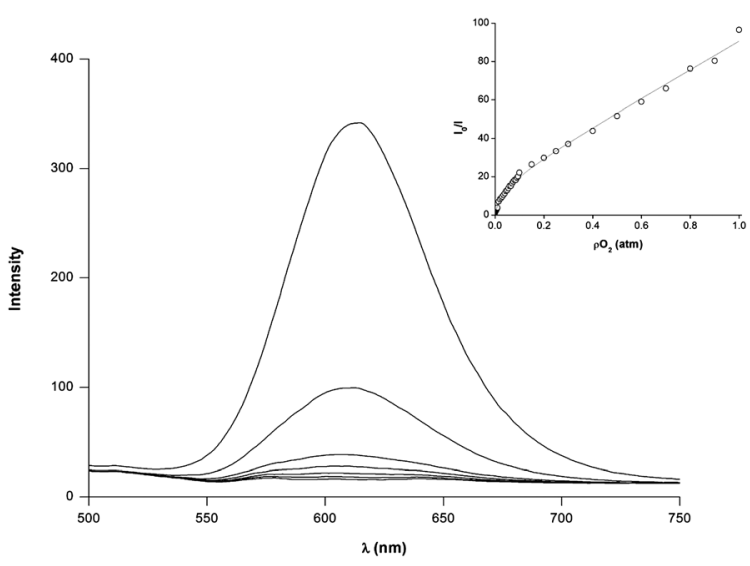

Fig. 2 Emission spectra of $\left[\mathrm{Ru}(\mathrm{dpp})_{3}\right]^{2+}-\mathrm{TiO}_{2}$ pigment upon exposure to (from top to bottom) $0,0.01,0.05,0.3,0.6$ and $1 \mathrm{~atm} \mathrm{O}_{2}$; inset is Stern-Volmer plot $\mathrm{O}=$ experimental data, solid line is 2 -site model fit to data.

Table 2 Quenching parameters of the $\left[R u(d p p)_{3}\right]^{2+}$ pigment and LDPE film (determined from luminescence intensity vs. $\mathrm{PO}_{2}$ studies)

\begin{tabular}{lcccl}
\hline $\begin{array}{l}\text { Indicator } \\
\text { type }\end{array}$ & $f_{01}$ & $\begin{array}{l}K_{\mathrm{SV} 1} \\
\left(\mathrm{~atm}^{-1}\right)\end{array}$ & $\begin{array}{l}K_{\mathrm{SV} 2} \\
\left(\mathrm{~atm}^{-1}\right)\end{array}$ & $\begin{array}{l}\mathrm{PO}_{2}(S=1 / 2) \\
(\mathrm{atm})\end{array}$ \\
\hline $\mathrm{TiO}_{2}$ pigment & $0.959 \pm 0.004$ & $459.7 \pm 44.2$ & $3.6 \pm 0.4$ & 0.002 \\
$\mathrm{LDPE}$ film & $0.24 \pm 0.01$ & $30.7 \pm 3.5$ & $0.65 \pm 0.02$ & 0.84
\end{tabular}

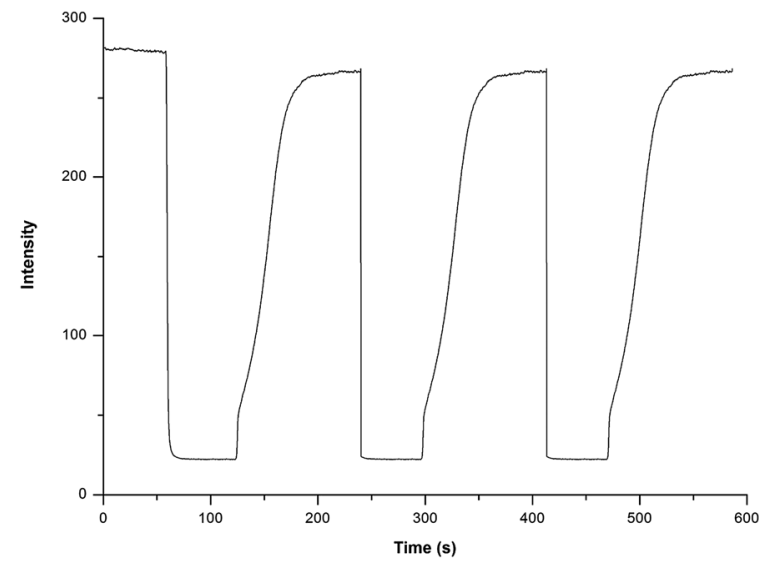

Fig. 3 Repeat response and recovery of $\mathrm{TiO}_{2}-\left[\mathrm{Ru}(\mathrm{dpp})_{3}\right]^{2+}$ pigment to alternating streams of 0 and $1 \mathrm{~atm} \mathrm{O}_{2}$.

is embedded in the polymer of a dried ink film, since in the latter case the oxygen must first dissolve and then diffuse through the polymer in order to quench the homogeneously dispersed lumophore.

In a separate experiment, the luminescence intensity response of the titania- $\left[\mathrm{Ru}(\mathrm{dpp})_{3}\right]^{2+}$ pigment towards repeated alternating streams of 0 atm and $1 \mathrm{~atm} \mathrm{O}_{2}$, and its response and recovery times, were measured by measuring the luminescence intensity as a function of time at $615 \mathrm{~nm}$, and switching the gas stream between pure $\mathrm{Ar}$ and $\mathrm{O}_{2}$ (Fig. 3). From this data, it was possible to determine the $50 \%$ response and recovery times, $t_{\downarrow 50}$ and $t_{\uparrow 50}$, defined as the time taken for the luminescence intensity to decrease/recover by $50 \%$ on switching from $\mathrm{Ar} \rightarrow \mathrm{O}_{2}$, and back again, which were $2 \mathrm{~s}$ and $25 \mathrm{~s}$, respectively.

The extremely rapid change in luminescence of the $\left[\mathrm{Ru}(\mathrm{dpp})_{3}\right]^{2+}$ bound to the surface of the $\mathrm{TiO}_{2}$ particle pigment upon exposure to $\mathrm{O}_{2}(\leq 2 \mathrm{~s})$ is also likely due to the large surface area of the pigment $\left(c a .50 \mathrm{~m}^{2} \mathrm{~g}^{-1}\right)$ which provides much greater access for the $\mathrm{O}_{2}$ to the quenchable, surface-bound lumophore. Note that in this work, the relative humidity sensitivity of the pigment was not evaluated and may alter the $\mathrm{PO}_{2}(S=1 / 2)$ value reported in Table 2 .

\section{2 $\mathrm{TiO}_{2}-\left[\mathrm{Ru}(\mathrm{dpp})_{3}\right]^{2+}-$ pigmented LDPE film as an $\mathrm{O}_{2}$ indicator}

3.2.1 Luminescence intensity studies. Upon extrusion of the $\mathrm{TiO}_{2}-\left[\mathrm{Ru}(\mathrm{dpp})_{3}\right]^{2+}$ lumophore in LDPE, the luminescence properties of the polymer film were studied and the emission maximum of the film observed at $600 \mathrm{~nm}$, i.e. slightly blueshifted, but otherwise similar in shape, to that of the lumophore ion-pair on the naked pigment (compare the data in Fig. 2 and 4). The intensity of this luminescence was measured as a function of $\mathrm{PO}_{2}$, the results of which are shown in Fig. 4, and a corresponding Stern-Volmer plot generated from the data (inset, Fig. 4). As expected, and as seen for the $\mathrm{TiO}_{2}-\left[\mathrm{Ru}(\mathrm{dpp})_{3}\right]^{2+}$ pigment, the Stern-Volmer plot showed negative deviation from linearity, and as such was analysed using the 2 site model and 


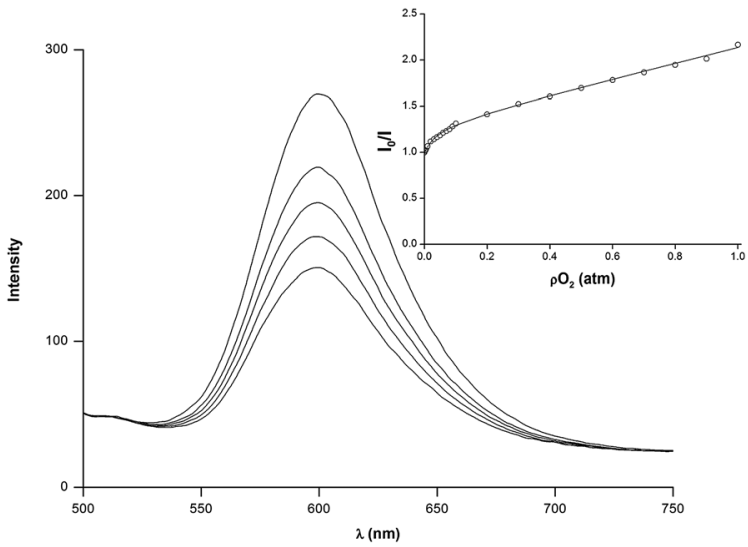

Fig. 4 Emission spectra of $\left[\mathrm{Ru}(\mathrm{dpp})_{3}\right]^{2+}$ LDPE film upon exposure to (from top to bottom) $0,0.1,0.3,0.6$ and 1 atm $\mathrm{O}_{2}$; inset is Stern-Volmer plot $\mathrm{O}=$ experimental data, solid line is 2 -site model fit to data.

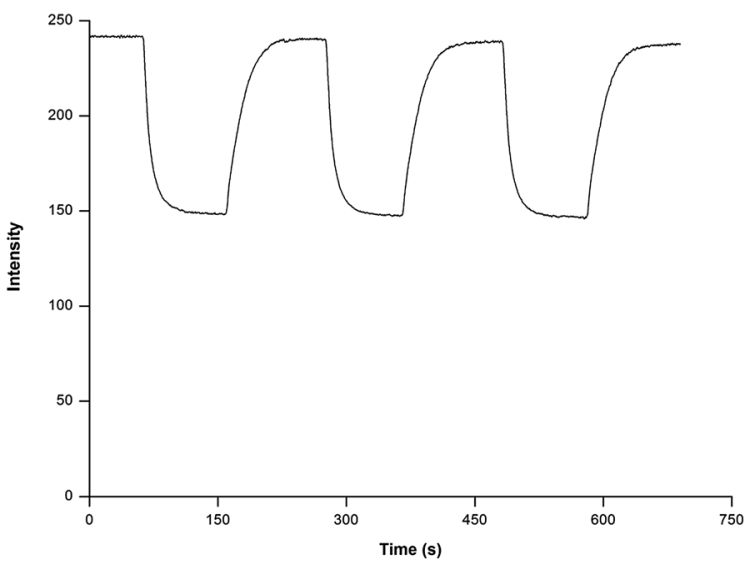

Fig. 5 Repeat response and recovery of $\mathrm{TiO}_{2}-\left[\mathrm{Ru}(\mathrm{dpp})_{3}\right]^{2+}$ pigmented LDPE film to alternating streams of 0 and $1 \mathrm{~atm} \mathrm{O}_{2}$.

eqn (3); the calculated optimum fit quenching parameters for which are presented in Table 2.

A study of the variation in luminescence intensity upon switching the gas stream alternately from $\mathrm{O}_{2}$ to Ar was carried out and the results are illustrated in Fig. 5, from which values for $t_{\downarrow 50}$ and $t_{\uparrow 50}$ were calculated to be $6 \mathrm{~s}$ and $14 \mathrm{~s}$, respectively. These results show that the heterogeneous lumophore ion-pair $\mathrm{O}_{2}$ sensitive film has a much (ca. 420 times) reduced $\mathrm{O}_{2}$ sensitivity compared to the pigment alone most probably due to the low $\mathrm{O}_{2}$ permeability in LDPE $\left(2.3 \times 10^{10} \mathrm{~cm}^{3} \mathrm{~cm} \mathrm{~cm}^{-2} \mathrm{~s}^{-1} \mathrm{~cm}\right.$ $\mathrm{Hg}^{-1}$ (ref. 25)). However, despite this, the extruded $\mathrm{TiO}_{2}-$ $\left[\mathrm{Ru}(\mathrm{dpp})_{3}\right]^{2+}$ pigmented LDPE film reported here is of comparable $\mathrm{O}_{2}$ sensitivity to the $\left[\mathrm{Ru}(\mathrm{dpp})_{3}\right]^{2+}$-silicone sensors previously reported and listed in Table 2, which is possibly not too surprising given the similarity in $\mathrm{O}_{2}$ permeability, i.e. $P_{\mathrm{M}}$ (silicone) $=6.2 \times 10^{10} \mathrm{~cm}^{3} \mathrm{~cm} \mathrm{~cm}^{-2} \mathrm{~s}^{-1} \mathrm{~cm} \mathrm{Hg}^{-1} \cdot{ }^{26}$

Finally, the luminescence responses of the $\mathrm{TiO}_{2}-\left[\mathrm{Ru}(\mathrm{dpp})_{3}\right]^{2+}$ pigmented extruded LDPE film to $0,0.21$ and 1 atm $\mathrm{O}_{2}$ in the presence $(100 \%)$ and absence (0\%) of relative humidity (RH) were measured, and the results indicated little, if any, change in

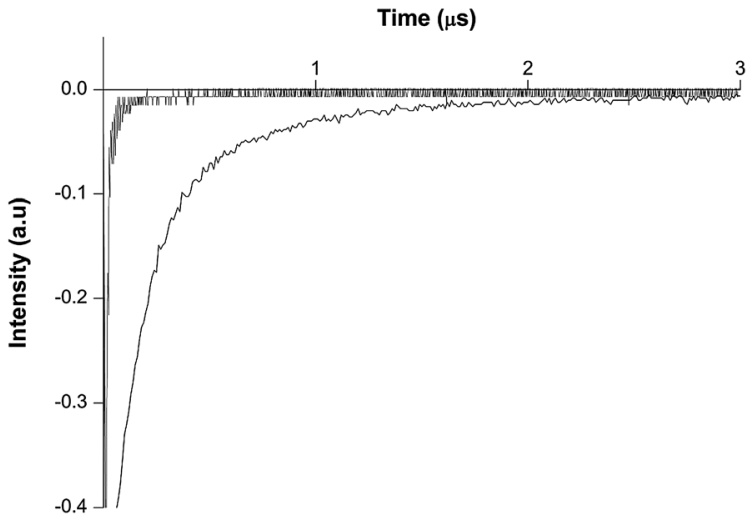

Fig. 6 Typical decay curves of the $\mathrm{TiO}_{2}-\left[\mathrm{Ru}(\mathrm{dpp})_{3}\right]^{2+}$ pigmented LDPE film in the absence and presence of $\mathrm{O}_{2}$

the $\mathrm{O}_{2}$ sensitivity of the indicator to changes in RH. This is most likely due to the low permeability of water in polyethylene $(0.05 \times$ $10^{10} \mathrm{~cm}^{3} \mathrm{~cm} \mathrm{~cm}^{-2} \mathrm{~s}^{-1} \mathrm{~cm} \mathrm{Hg}^{-1}$ ), which is in striking contrast to silicone rubber $\left(51.8 \times 10^{10} \mathrm{~cm}^{3} \mathrm{~cm} \mathrm{~cm}^{-2} \mathrm{~s}^{-1} \mathrm{~cm} \mathrm{Hg}^{-1}\right) .{ }^{27}$

\subsubsection{Luminescence lifetime studies}

Quenching analysis of the extruded film was additionally carried out via lifetime measurements, and typical nanosecond flash photolysis luminescence decay curves of the lumophore in the extruded film in the presence and absence of $\mathrm{O}_{2}$ are shown in Fig. 6.

As expected, these decays were not described by simple first order kinetics, as expected for homogeneous solutions, but rather a multi-exponential decay was observed. Such decays fit eqn (5), as proposed by Demas, ${ }^{28}$ for a two quenching domain, heterogeneous system:

$$
i(t)=\sum_{i} \alpha_{i} \mathrm{e}^{\frac{-t}{\tau_{i}}}
$$

where $i(t)$ is the response of the system, $\alpha_{i}$ is the pre-exponential weighting factor for the $i$ domains, and $\tau$ is the lifetime. From

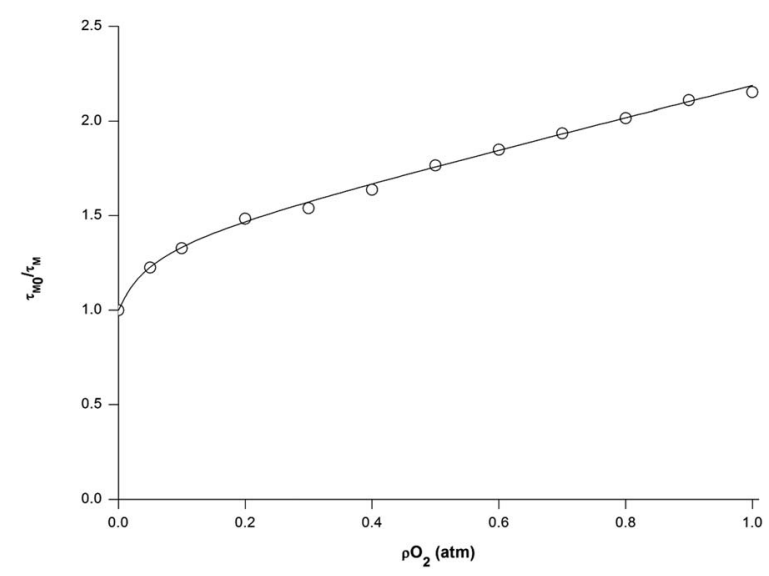

Fig. 7 Lifetime Stern-Volmer plot of $\mathrm{TiO}_{2}-\left[\mathrm{Ru}(\mathrm{dpp})_{3}\right]^{2+}$ pigmented extruded LDPE film: $O$ experimental data, solid line is two-site model fit to the data; $f_{01}=$ $0.29 \pm 0.02, K_{\mathrm{sV} 1}=26.4 \pm 7.3 \mathrm{~atm}^{-1}, K_{\mathrm{sV} 2}=0.59 \pm 0.05 \mathrm{~atm}^{-1}, \mathrm{PO}_{2}(S=1 / 2)=$ $0.78 \mathrm{~atm}$. 
the decay data fitted to eqn (5), it is possible to calculate the preexponentially weighted mean lifetime, $\tau_{\mathrm{m}}$, from eqn (6).

$$
\tau_{\mathrm{m}} \equiv \frac{\sum \alpha_{i} \tau_{i}}{\sum \alpha_{i}}
$$

These weighted lifetimes can be compared directly to the intensity values gained from the fluorimetry work, via a corresponding Stern-Volmer (lifetime) plot, the results of which are illustrated in Fig. 7. The calculated quenching parameters derived from fitting the data in Fig. 7 to eqn (3) are in extremely good agreement with those calculated from the intensity data illustrated in Fig. 4, notably a value for $\mathrm{PO}_{2}(S=1 / 2)$ of 0.78 atm can be calculated from the lifetime study that compares well with that from the luminescence intensity study (see Fig. 4), of 0.84 atm.

\section{Conclusions}

Most previous work on $\mathrm{O}_{2}$ sensors involving $\mathrm{Ru}(\mathrm{II})$ diimine complexes as the lumophores have combined the cationic lumophores with a lipophilic anion, rendering the homogeneous dye-anion ion-pair lipophilic, and so soluble in a solvent containing a polymer such as polystyrene or silicone. In contrast, in this work $-\left[\mathrm{Ru}(\mathrm{dpp})_{3}\right]^{2+}$ is ion-paired to the surface of $\mathrm{TiO}_{2}$ nanoparticles to produce a heterogeneous $\mathrm{O}_{2}$ sensing pigment, with a strikingly high $\mathrm{O}_{2}$ sensitivity, most likely due to the ready access afforded to the ambient $\mathrm{O}_{2}$ to the quenchable luminescent dye, $\left[\mathrm{Ru}(\mathrm{dpp})_{3}\right]^{2+}$. This pigment was extruded in LDPE to form a thin, flexible, plastic film which was readily quenched by $\mathrm{O}_{2}$. A major drawback of using a homogeneous ion-pair polymer ink is the need for a largely inflexible, support on which the ink must be cast and dried prior to $\mathrm{O}_{2}$ sensing. ${ }^{11,12,15,16}$ In contrast, extrusion of polymer films containing the $\mathrm{O}_{2}$ sensitive lumophore (in this case in pigment form) produces a fully flexible and self-supporting, ready to use, $\mathrm{O}_{2}$ sensitive film. Other reported problems with the traditional $\mathrm{O}_{2}$ sensors include: dye leaching in solvents which cause the polymer to swell, such as acetone, ${ }^{12}$ and water, ${ }^{11}$ film curling, ${ }^{12}$ water condensation on the film surface, ${ }^{12}$ and a reduction of sensitivity at high $\mathrm{RH}^{11}$ The LDPE film produced in this work shows none of these undesirable characteristics and from the results of this work, dyepigment pairing followed by extrusion into a polymer appears a promising route to make $\mathrm{O}_{2}$ sensitive, flexible, polymer films.

\section{References}

1 B. Lei, B. Lei, H. Zhang, S. Lu, Z. Zheng, W. Li and Y. Wang, Adv. Funct. Mater., 2006, 16, 1883.

2 C. S. Chu, Appl. Opt., 2011, 50, E145.
3 A. N. Watkins, R. Weriner, J. D. Jordan, W. Xu, J. N. Demas and F. U. Bright, Appl. Spectrosc., 1998, 52, 751.

4 L. C. Clark, R. Wolf, D. Granger and Z. Taylor, J. Appl. Physiol., 1953, 6, 189.

5 A. Mills, Platinum Met. Rev., 1997, 41, 115.

6 A. Mills and A. Lepre, Anal. Chem., 1997, 69, 4653.

7 A. Mills and M. Thomas, Analyst, 1997, 122, 63.

$8 \mathrm{~J}$. N. Demas and B. A. DeGraff, in Topics in Fluorescence Spectroscopy, ed. J. R. Lakowicz, Plenum Press, New York and London, 1994, vol. 4, p. 71.

9 J. N. Demas, B. A. DeGraff and W. Xu, Anal. Chem., 1995, 67, 1377.

10 O. S. Wolfbeis, M. J. P. Leiner and H. E. Posch, Mikrochim. Acta, 1986, 90, 359.

11 I. Klimant and O. Wolfbeis, Anal. Chem., 1995, 67, 3160.

12 J. R. Bacon and J. N. Demas, Anal. Chem., 1987, 59, 2780.

13 A. Mills and F. C. Williams, Thin Solid Films, 1997, 306, 163.

14 E. R. Carraway, J. N. Demas, B. A. DeGraff and J. R. Bacon, Anal. Chem., 1991, 63, 5337.

15 P. Hartmann, M. J. P. Leiner and M. E. Lippitsch, Anal. Chem., 1995, 67, 88.

16 C. Preininger, I. Kilmant and O. S. Wolfbeis, Anal. Chem., 1994, 66, 1841.

17 http://www.oxysense.com, accessed June 2013.

18 J. W. Gregory, K. Asai, M. Kameda, T. Liu and J. P. Sullivan, Journal of Aerospace Engineering, 2008, 222, 249.

19 R. Erkins and P. Edwards, Clin. Chem., 1997, 43, 1824.

20 B. D. MacCraith, C. McDonagh, G. O'Keefe, E. T. Keyes, J. G. Vos, B. O'Kelly and J. F. McGlip, Analyst, 1993, 118, 385. 21 T. Ohno, K. Surukawa, K. Tokieda and M. Matsumura, J. Catal., 2001, 203, 82.

22 R. O. James and G. A. Parks, Characterization of aqueous colloids by their electrical double-layer and intrinsic chemical properties, in Surface and Colloidal Science, ed. E. Matijevic, Plenum Press, New York, ch. 2, 1982.

23 I. Bergman, Nature, 1968, 218, 396.

24 T. Hiemstra and W. H. Van Riemsdijk, J. Colloid Interface Sci., 2006, 301, 1.

$25 \mathrm{H}$. Zhang and A. Cloud, The Permeability Characteristics of Silicone Rubber, in Global Advances in Materials and Process Engineering proceedings, November 6-9, 2006, Dallas, pp. 72-75.

26 S. Marias, J. M. Saiter, C. Devallencourt, Q. T. Nguyen and M. Métayer, Polym. Test., 2002, 21, 425.

27 Shin-Etsu, Characteristic properties of silicone rubber compounds, Tokyo, Japan, 2005.

28 E. R. Carraway, J. N. Demas and B. A. DeGraff, Anal. Chem., 1991, 63, 332. 